\title{
Etching a Fiber Post Surface with High-concentration Bleaching Agents
}

\author{
MS Menezes • AL Faria-e-Silva • FP Silva \\ GR Reis $\bullet$ CJ Soares $\bullet$ THS Stape \\ LR Martins
}

\section{Clinical Relevance}

High-concentration bleaching can etch the post surface and improve bonding of the resin core and resin cement.

\section{Summary}

Introduction: Commonly, resin composites/cements fail to achieve proper bonding to fiber posts when their surfaces have not been previously etched. This study evaluated the effect of the concentration and application mode of hydrogen peroxide on the surface topography and bond strength of resin composite to glassfiber posts.

Methods and Materials: Fiber posts were immersed in $24 \%$ or $35 \%$ solutions (a high-con-

*Murilo S Menezes, PhD, DMD, DDS, Federal University of Uberlândia, Department of Operative Dentistry and Dental Materials, Uberlândia, Brazil

André L Faria-e-Silva, DDS, MD, PhD, Federal University of Sergipe, Department of Dentistry, Aracaju, Brazil

Fernanda P Silva, Federal University of Uberlândia, Department of Operative Dentistry and Dental Materials, Uberlândia, Brazil

Giselle R Reis, Federal University of Uberlândia, Department of Operative Dentistry and Dental Materials, Uberlândia, Brazil

Carlos J Soares, DDS, MS, PhD, School of Dentistry, Federal University of Uberlândia, Operative Dentistry and Dental Materials, Brazil

Thiago HS Stape, DDS, MS, State University of Campinas, centration bleaching agent) of hydrogen peroxide $\left(\mathrm{H}_{2} \mathrm{O}_{2}\right)$, or these solutions were applied over the post surface using a microbrush $(n=10)$. Posts without any treatment were used as a control. After etching, the posts were silanated and an adhesive was applied. The posts were positioned in a mold, and a resin composite was incrementally inserted and light-cured. The post/resin assembly was serially sectioned into several beams that were subjected to a tensile bond strength test. The data were subjected to the two-way analysis of variance and Tukey test $(\alpha=0.05)$. The Dunnet's test was used to compare the experimental conditions to the control. The surface topography was analyzed using scanning electronic microscopy.

Department of Restorative Dentistry, Piracicaba, Brazil

Luis R Martins, DDS, MD, PhD, State University of Campinas, Department of Restorative Dentistry, Piracicaba, Brazil

*Corresponding author: Av. Para 1720, Bloco 2B, Campus Umuarama, Uberlândia, MG 38400-902 Brazil; e-mail: murilomenezes@foufu.ufu.br

DOI: $10.2341 / 12-270-\mathrm{L}$ 
Results: The non-etched post presented a relatively smooth surface without fiber exposure. Except for the application of $24 \% \mathrm{H}_{2} \mathrm{O}_{2}$, the other experimental conditions increased the number of exposed fibers and bond strength in relation to the control. Although immersion resulted in higher values for the $24 \% \mathrm{H}_{2} \mathrm{O}_{2}$ application, the mode of application did not alter bond strength when $35 \% \mathrm{H}_{2} \mathrm{O}_{2}$ was used.

Conclusions: The effect of the mode of application of $\mathrm{H}_{2} \mathrm{O}_{2}$ depended on its level of concentration. A high-concentration bleaching agent improved the bond strength of the resin composite to the post surface, regardless of which mode was used.

\section{INTRODUCTION}

Despite biomechanical advantages, a relatively high rate of failure has been demonstrated in fiber postretained restorations. ${ }^{1,2}$ However, fewer irreparable failures have been associated with fiber posts than with traditional metallic cast posts. ${ }^{3}$ Post debonding is one possible failure caused by the complexity of bonding to root canals. ${ }^{4,5}$ Another commonly reported failure is fracture of the post and/or core. ${ }^{6}$ In addition, debonding increases the risk of fracture. ${ }^{7}$ Thus, proper bonding of resin cement to the post and the dentin of the root canal is essential for improving the success of fiber post-retained restorations.

Most failures of post-retained restorations result from debonding, and the cement/dentin interface is the weakest link. ${ }^{8-10}$ However, bonding between the fiber post and core buildup composites is also essential to the success of the restoration. The organic component of fiber posts is generally composed of epoxy resin, which has a high degree of conversion and is highly crosslinked. ${ }^{11,12}$ Thus, this polymer matrix is virtually unable to react with the monomers of resin cements. Among the various treatments proposed to improve adhesion to the fiber-post surface, silanization has been assessed in several laboratory studies. ${ }^{13,14}$ However, silane coupling agents, commonly used in dentistry, react with glass fibers and may not bond well to the organic component. ${ }^{15}$ Therefore, treating the post in order to roughen the surface and expose the glass fibers has been suggested; it allows for micromechanical interlocking of the adhesive/cement with the post. ${ }^{12}$ In addition, chemical bonding may be established by using silane. ${ }^{12,15-17}$

Among chairside procedures, post-surface treatment with hydrogen peroxide $\left(\mathrm{H}_{2} \mathrm{O}_{2}\right)$ is a simple and effective method to improve the bonding of adhesive/ cement to the fiber post. Selectively, $\mathrm{H}_{2} \mathrm{O}_{2}$ removes the surface layer of epoxy resin and exposes the glass fibers,${ }^{15,18}$ resulting in chemical bonding between the adhesive/cement and the exposed fibers due to the ability of silane to couple with hydroxide-covered surfaces (such as glass fibers). ${ }^{19,20}$ A previous study demonstrated that immersing a fiber post in a solution of $24 \% \mathrm{H}_{2} \mathrm{O}_{2}$ improves bond strength to the post in one minute, which is a feasible clinical time. ${ }^{18}$ Clinically, however, the application of $\mathrm{H}_{2} \mathrm{O}_{2}$ over the post is more favorable than immersion. Furthermore, limited information is available regarding the use of high-concentration bleaching agents on the post etching commonly available in dental offices.

Thus, the aim of this study was to evaluate the effect of concentrations of $\mathrm{H}_{2} \mathrm{O}_{2}$, including a highconcentration bleaching agent, and mode of use on the bond strength between resin composite and glass fiber posts. In addition, the surface of fiber posts was evaluated using scanning electronic microscopy (SEM). The null hypothesis tested was that neither the $\mathrm{H}_{2} \mathrm{O}_{2}$ concentration nor the mode used would affect bond strength.

\section{METHODS AND MATERIALS}

\section{Microtensile Bond Strength Test}

A glass fiber-reinforced epoxy post system (White Post DC3, FGM, Joinvile, SC, Brazil) was used. Polyvinylsiloxane impression material (Aquasil, Dentsply DeTrey, Konstanz, Germany) molds were obtained to standardize core buildup on the posts. Two plastic plates $(10 \mathrm{~mm}$ long $\times 4 \mathrm{~mm}$ wide $\times 1 \mathrm{~mm}$ thick) were attached along the post surface; each plate was placed opposite the other, and both were located in the same plane using cyanoacrylate adhesive. The post attached to the plates was centrally positioned into a polyvinyl chloride (PVC) tube (20 $\mathrm{mm}$ inner diameter $\times 15 \mathrm{~mm}$ high) (Figure $1 \mathrm{~A}$ ), and the impression material was placed into the tube. The post attached to the plates was removed after polymerization of the polyvinylsiloxane (Figure $1 B)$, leaving a space to insert the post and resin composite (Figure 1C).

A commercially available $35 \% \quad \mathrm{H}_{2} \mathrm{O}_{2}$ bleaching agent (Whiteness HP Max, FGM) or a $24 \% \mathrm{H}_{2} \mathrm{O}_{2}$ solution (Dinâmica, São Paulo, SP, Brazil) was used to etch the posts. The fiber posts $(n=10)$ immersed in the solution/bleaching agent were placed in Eppendorf tubes, or the solution/bleaching agent was applied over the post surface using a microbrush. 


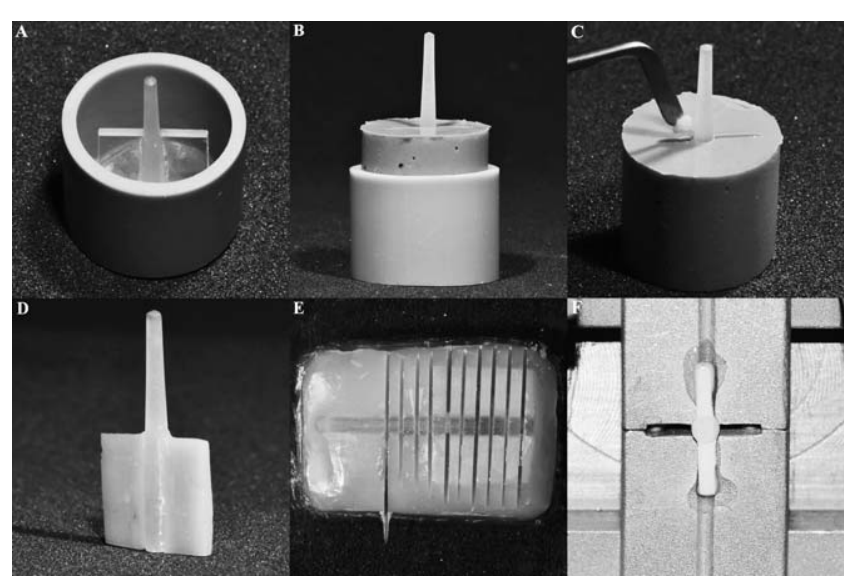

Figure 1. Illustration of mold and sample preparation. (A): Fiber post with plastic plates attached and positioned into PVC tube. (B): Mold removal from PVC tube. (C): Post positioned into the mold created and insertion of composite resin. (D): Specimen with resin composite bonded to fiber post. (E): Sectioned specimen. (F) Specimen attached to tensile device.

All etching protocols were performed for one minute. After etching with $\mathrm{H}_{2} \mathrm{O}_{2}$, the posts were rinsed with distilled water and air-dried. Ten posts were rinsed only with water and used as a control. A silanecoupling agent was applied in a single layer on the post surfaces and gently air-dried after 60 seconds. The adhesive resin Scotchbond Multi-Purpose Plus (3M ESPE, St Paul, MN, USA) was applied over the post surface and light-cured for 20 seconds using a light-emitting diode light-curing device (Radii-Cal, SDI, Bayswater, Victoria, Australia). The post was positioned into the corresponding space of the mold, and a microhybrid resin composite (Opallis, FGM) was incrementally inserted to fill the mold, with each increment being light-cured for 40 seconds. The samples were stored for 24 hours under $100 \%$ humidity conditions.

The specimens were serially sectioned using a lowspeed saw (Extec, Enfield, CT, USA) to obtain 1-mm thick sections. The beams were attached to the flat grips of a microtensile testing device and tested in a mechanical testing machine (EMIC DL 2000, São José dos Pinhais, PR, Brazil) at a crosshead speed of $0.5 \mathrm{~mm} /$ minute until failure. The average value of the beams in the same specimen was recorded as the microtensile bond strength $(\mathrm{MPa})$ for that specimen. Data for the experimental conditions were analyzed using two-way analysis of variance, followed by the Tukey's post-hoc test $(\alpha=0.05)$. The factors evaluated were concentration of $\mathrm{H}_{2} \mathrm{O}_{2}$ and mode of use. The Dunnet's test was used to compare experimental conditions to control conditions $(\alpha=0.05)$.

\begin{tabular}{|lcc|}
\hline Table 1: & Means (SD) for Tensile Bond Strength $(\mathrm{MPa})^{a}$ \\
\hline & \multicolumn{2}{|c|}{ Concentration of $\mathrm{H}_{2} \mathrm{O}_{2}$} \\
\cline { 2 - 3 } Mode of Use & $\mathbf{2 4 \%}$ & $35 \%$ \\
\hline Immersion & $18.7(3.7) \mathrm{Aa}^{*}$ & $21.1(4.1) \mathrm{Aa}^{*}$ \\
\hline Application & $13.4(3.0) \mathrm{Bb}$ & $21.0(2.8) \mathrm{Aa}^{*}$ \\
\hline $\begin{array}{l}\text { a Distinct uppercase letters in the same line indicate differences between } \\
\text { concentrations; distinct lowercase letters in the same column indicate } \\
\text { differences between application mode }(\alpha=0.05) . \\
\text { * Differs from the control group (11.0 } \pm 4.1) \text { using Dunnet's test }(\alpha=0.05) .\end{array}$ \\
\hline
\end{tabular}

\section{Surface Topography}

Two additional fiber posts per group were used to analyze the surface topography using SEM. After treatment with $\mathrm{H}_{2} \mathrm{O}_{2}$ (the control did not receive any treatment), the specimens were ultrasonically cleansed for 10 minutes using deionized water, followed by immersion in 96\% ethanol for two minutes and air-dried. The posts were coated with gold (MED 010, Bal-Tec AG, Balzers, Liechtenstein) and evaluated by SEM (LEO 435 VP, Nano Technology Systems Division of Carl Zeiss SMT, Cambridge, UK) with magnifications ranging from 80 to $4000 \times$. The microscope operated at $20 \mathrm{KV}, \mathrm{WD}=10$ $\mathrm{mm}$, and spot size ranged from $25 \mathrm{pA}$ to $100 \mathrm{pA}$. Fiber integrity and homogeneity along the treated surface and at the resin-matrix fiber interface was thoroughly analyzed along the entire post surface extension.

\section{RESULTS}

\section{Microtensile Bond Strength Test}

The statistical analysis showed a significant effect for concentration of $\mathrm{H}_{2} \mathrm{O}_{2}(p<0.001)$, application mode $(p=0.02)$, or the interaction between the factors $(p=0.02)$. The results are shown in Table 1 . For immersion of the post into $\mathrm{H}_{2} \mathrm{O}_{2}$ solutions, there was no difference between concentrations, although using $35 \% \mathrm{H}_{2} \mathrm{O}_{2}$ resulted in higher bond strength when the solutions were applied over the post surface. The mode of use did not affect bond strength for $35 \% \mathrm{H}_{2} \mathrm{O}_{2}$. Immersion into the solution resulted in higher values when $24 \% \mathrm{H}_{2} \mathrm{O}_{2}$ was used. Except for the application of $24 \% \mathrm{H}_{2} \mathrm{O}_{2}$, the other experimental conditions resulted in higher bond strength than the control $(11.0 \pm 4.1 \mathrm{MPa})$.

\section{Surface Topography}

Representative SEM images of each experimental condition and the control are shown in Figure 2. Figure 2A shows epoxy resin covering the glass fibers of the post without treatment and some areas with exposed fibers and flaws. The application of 


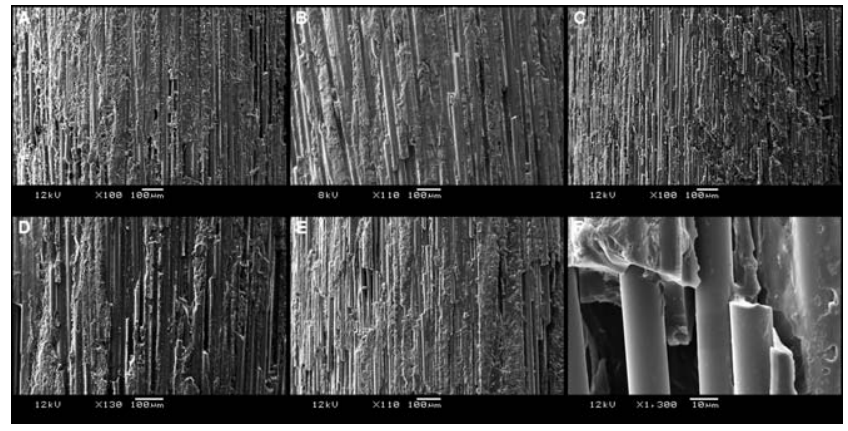

Figure 2. Analysis of the surface topography by SEM. (A): Without treatment. (B) Application of 24\% $\mathrm{H}_{2} \mathrm{O}_{2}$ (C): Immersion of fiber post into solution of 24\% $\mathrm{H}_{2} \mathrm{O}_{2}$. (D): Application of 34\% $\mathrm{H}_{2} \mathrm{O}_{2}$. (E and F): Immersion of fiber post into solution of $35 \% \mathrm{H}_{2} \mathrm{O}_{2}$

$24 \% \mathrm{H}_{2} \mathrm{O}_{2}$ on the post surface did not effectively expose the glass fibers (Figure 2B). More exposed fibers were observed when the post was etched by immersion in $\mathrm{H}_{2} \mathrm{O}_{2}$ (both concentrations) or when $35 \% \mathrm{H}_{2} \mathrm{O}_{2}$ was applied (Figures $2 \mathrm{C}$ through $2 \mathrm{~F}$ ).

\section{DISCUSSION}

Several studies have evaluated chairside protocols to allow a chemo-mechanical bonding of resin-based material to fiber post surfaces. ${ }^{12,13,15-18,21-23}$ Sandblasting procedures with alumina particles ${ }^{21,22}$ or aluminum oxide particles modified by silica ${ }^{23}$ (Rocatec System, 3M ESPE) increase the roughness of the post surface and permit the mechanical bonding of resin-based materials to the fiber post. The use of Rocatec also allows chemical bonding by silanization due to the presence of the silica-coated surface. ${ }^{23}$ However, these devices are not available in some dental offices. Using $\mathrm{H}_{2} \mathrm{O}_{2}$ over the post surface has also demonstrated mechanical-chemical bonding of resin-based material to the fiber post. ${ }^{15,18}$ Frequently, $\mathrm{H}_{2} \mathrm{O}_{2}$ is available in dental offices as a result of bleaching procedures.

In the current study, fiber-post etching was performed for one minute, which is a feasible clinical time. Furthermore, a previous study demonstrated that immersing a post into $24 \%$ peroxide for one minute effectively improves the bond strength of resin composite to the post. ${ }^{18}$ However, for this period, the effect of the mode of use of $\mathrm{H}_{2} \mathrm{O}_{2}$ on the bond strength of resin composite to fiber post was concentration dependent. Thus, the null hypothesis tested was rejected. Only in the case of $24 \% \mathrm{H}_{2} \mathrm{O}_{2}$ did the mode of use affect bond strength, whereas immersing the post into the solution resulted in higher values. The application of $24 \% \mathrm{H}_{2} \mathrm{O}_{2}$ failed to effectively improve bond strength, which showed similar values to the control (without treatment). On the other hand, the mode of use for $35 \% \mathrm{H}_{2} \mathrm{O}_{2}$ did not affect bond strength nor did it improve values compared with the control.

The SEM analysis of the surface topography showed that the $24 \% \quad \mathrm{H}_{2} \mathrm{O}_{2}$ application did not increase the amount of exposed glass fibers. However, all experimental conditions increased the exposure of glass fibers without damaging them. It has been demonstrated that $\mathrm{H}_{2} \mathrm{O}_{2}$ solutions can partially dissolve epoxy resin, thus exposing the fibers. This dissolution is related to an electrophilic attack of $\mathrm{H}_{2} \mathrm{O}_{2}$ on the cured secondary amine. ${ }^{24}$ The spaces created between the fibers provide conditions for the micromechanical interlocking of the resin adhesive with the post. ${ }^{15,18}$ Furthermore, the exposed fibers bond chemically to the adhesive through the silane agent.

Based on the results of the current study, it is reasonable to assume that the ability of $\mathrm{H}_{2} \mathrm{O}_{2}$ to affect fiber post etching is related to the concentration and the application mode. The etching effect of $\mathrm{H}_{2} \mathrm{O}_{2}$ is based on oxidation of the post surface, thus breaking epoxy resin bonds. ${ }^{24,25}$ Although the oxidizing effect of $\mathrm{H}_{2} \mathrm{O}_{2}$ depends on the concentration of the radicals that are released, it dissociates and releases oxygenfree radicals, hydrogen-free radicals, water, and peridroxyl. ${ }^{26,27}$ A higher $\mathrm{H}_{2} \mathrm{O}_{2}$ concentration results in a higher oxidizing effect. This explains why $35 \%$ $\mathrm{H}_{2} \mathrm{O}_{2}$ is effective in improving bond strength independent of the application mode.

To the contrary, $24 \% \quad \mathrm{H}_{2} \mathrm{O}_{2}$ increased the bond strength of resin composite to fiber post compared with the control only when the post was immersed in the solution. The application of $24 \% \mathrm{H}_{2} \mathrm{O}_{2}$ resulted in similar values to those observed by the control. A possible explanation is that a single layer of peroxide applied on the post only reacted superficially with the epoxy resin once there was no replacement of radicals by oxidation. This replacement probably occurred when the post was immersed in $24 \% \mathrm{H}_{2} \mathrm{O}_{2}$ solution, thus increasing the potential for etching. Based on the results of this study, the application of high-concentration bleaching agents using a microbrush, which is frequently used in the dental practice for dental bleaching, is a feasible clinical procedure to improve the bond strength of resin composite to glass fiber posts.

It is important to emphasize that the current study only evaluated the bonding of a resin composite to a fiber post, simulating a core buildup. In this instance, an adhesive is applied over the post before the composite is inserted. Further studies are necessary to confirm that this protocol is also 
effective for resin cements applied directly over etched posts without using an intermediate adhesive layer. Differences in the composition and viscosity of materials can alter the results. ${ }^{23}$ Additionally, high stress generated by shrinkage of the resin cement during fiber-post cementation due the high C-factor of the root canal hinders bonding of the cement to the post. ${ }^{28}$ Stability of the bonding obtained with post etching, using a commercial high-concentration bleaching agent, must also be evaluated in future studies. It has been demonstrated that thermal cycling can alter the bond strength of resin-based material to fiber posts. ${ }^{29}$

\section{CONCLUSIONS}

Within the limitations of the current study, the following conclusions can be made:

- The mode of use of peroxide affected bond strength of the resin composite only when $24 \% \mathrm{H}_{2} \mathrm{O}_{2}$ was used, where immersion resulted in the highest mean.

- The use of a high-concentration bleaching agent over the fiber post improved bond strength of the resin composite to the post surface.

\section{Conflict of Interest}

The authors of this manuscript certify that they have no proprietary, financial, or other personal interest of any nature or kind in any product, service, and/or company that is presented in this article.

\section{(Accepted 8 October 2012)}

\section{REFERENCES}

1. Nauman M, Koelpi M, Beuer F, \& Meyer-Luckel H (2010) 10-year survival evaluation for glass-fiber-supported postendodontic restoration: a prospective observation clinical study Journal of Endodontics 38(4) 432-435. http://dx.doi.org/10.1016/j.joen.2012.01.003.

2. Schmitter M, Hamadi K, \& Rammelsberg P (2011) Survival of two post systems-five-year results of a randomized clinical trial Quintessence International 42(10) 843-850.

3. Ghavamnasiri M, Maleknejad F, Ameri H, Moghaddas MJ, Farzaneh F, \& Chasteen JE (2011) A retrospective clinical evaluation of success rate in endodontic-treated premolars restored with composite resin and fiber reinforced composite posts Journal of Conservative Dentistry 14(4) 378-382. http://dx.doi.org/10.4103/0972-0707. 8723.

4. Ferrari M, Cagidiaco MC, Grandini S, De Sanctis M, \& Goracci C (2007) Post placement affects survival of endodontically treated premolars Journal of Dental Research 86(6) 729-734. http://dx.doi.org/10.1177/ 154405910708600808 .
5. Cagidiaco MC, García-Godoy F, Vichi A, Grandini S, Goracci C, \& Ferrari M (2008) Placement of fiber prefabricated or custom made posts affects the 3-year survival of endodontically treated premolars American Journal of Dentistry 21(3) 179-184.

6. Naumann M, Blankenstein F, \& Dietrich T (2005) Survival of glass fiber reinforced composite post restorations after 2 years-an observational clinical study Journal of Dentistry 33(4) 305-312. http://dx.doi.org/10. 1016/j.jdent.2004.09.005.

7. Santos AF, Meira JB, \& Tanaka CB (2010). Can fiber posts increase root stress and reduce fracture? Journal of Dental Research 89(6) 587-591. http://dx.doi.org/10.1177/ 0022034510363382.

8. Boschian Pest L, Cavalli G, Bertani P, \& Gagliani M (2002) Adhesive post-endodontic restorations with fiber posts: push-out tests and SEM observations Dental Materials 18(8) 596-602. http://dx.doi.org/10.1016/ S0109-5461(02)0003-9.

9. Bitter K, Meyer-Lueckel H, Priehn K, Kanjuparambil JP, Newmann K, \& Kielbassa AM (2006) Effects of luting agent and thermocycling on bond strengths to root canal dentine International Endodontic Journal 39(10) 809818. http://dx.doi.org/10.1111/j.1365-2591.2006.01155.x.

10. Bitter K, Perdigão J, Exner M, Neumann K, Kielbassa AM, \& Sterzenbach G (2012) Reliability of fiber post bonding to root canal dentin after simulated clinical function in vitro Operative Dentistry 37(4) 397-405. http:// dx.doi.org/10.2341/11-066-L.

11. Lassila LV, Tanner J, Le Bell AM, Narva K, \& Vallittu PK (2004) Flexural properties of fiber reinforced root canal posts Dental Materials 20(1) 29-36. http://dx.doi. org/10.1016/S0109-5641(03)00065-4.

12. Monticelli F, Osorio R, Sadek FT, Radovic I, Toledano M, \& Ferrari M (2008) Surface treatments for improving bond strength to prefabricated fiber posts: a literature review Operative Dentistry 33(3) 346-355. http://dx.doi. org/10.2341/07-86.

13. Novais VR, Simamotos Júnior PC, Rontani RM, CorrerSobrinho L, \& Soares CJ (2012) Bond strength between fiber posts and composite resin core: influence of temperature on silane coupling agents Brazilian Dental Journal 23(1) 8-14. http://dx.doi.org/10.1590/ S0103-64402012000100002.

14. Davis P, Melo LS, Foxton RM, Sherriff M, Pilecki P, Mannocci F, \& Watson TF (2010) Flexural strength of glass fiber-reinforced posts bonded to dual-cure composite resin cements European Journal of Oral Sciences 118(2) 197-201. http://dx.doi.org/10.1111/j.1600-0722.2010. 00721.x.

15. Monticelli F, Toledano M, Tay FR, Sadek FT, Goracci C, \& Ferrari M (2006) A simple etching technique for improving the retention of fiber posts to resin composites Journal of Endodontics 32(1) 44-47. http://dx.doi.org/10. 1016/j.joen.2005.10.005.

16. Monticelli F, Toledano M, Tay FR, Cury AH, Goracci C, \& Ferrari M (2006) Post-surface conditioning improves interfacial adhesion in post/core restorations Dental Materials 22(7) 602-609. http://dx.doi.org/10.1016/j. dental.2005.05.018. 
17. Vano M, Goracci C, Monticelli F, Tognini F, Gabriele M, Tay FR, \& Ferrari M (2006) The adhesion between fibre posts and composite resin cores: the evaluation of microtensile bond strength following various surface chemical treatments to posts International Endodontic Journal 39(1) 31-39. http://dx.doi.org/10.1111/j.1365-2591.2005. 01044.x.

18. de Sousa Menezes M, Queiroz EC, Soares PV, Faria-eSilva AL, Soares CJ, \& Martins LR (2011) Fiber post etching with hydrogen peroxide: effect of concentration and application time Journal of Endodontics 37(3) 398402. http://dx.doi.org/10.1016/j.joen.2010.11.037.

19. Matinlinna JP, Özcan M, Lassila LVJ, \& Vallittu PK (2004) The effect of a 3-methacryloxypropyltrimethoxysilane and vinyltriisopropoxysilane blend and tris (3trimethoxysilylpropyl) isocyanurate on shear bond strength of composite resin to titanium metal Dental Materials 20(9) 804-813. http://dx.doi.org/10.1016/j. dental.2003.10.009.

20. Daniels MW, \& Francis LF (1998) Silane adsorption behavior, microstructure, and properties of glycidoxypropyltrimethoxysilane-modified colloidal silica coatings Journal of Colloid and Interface Science 205(1) 191-200. http://dx.doi.org/10.1006/jcis.1998.5671.

21. Jongsma LA, Kleverlaan CJ, \& Feilzer AJ (2010) Influence of surface pretreatment of fiber posts on cement delamination Dental Materials 26(9) 901-907. http://dx. doi.org/10.1016/j.dental.2010.05.005.

22. Mosharraf R, \& Yazdi NB (2012) Comparative evaluation of effects of different surface treatment methods on bond strength between fiber post and composite core Journal of Advanced Prosthodontics 4(2) 103-108. http://dx.doi.org/ 10.4047/jap.2012.4.2.103.
23. Mazzitelli C, Papacchini F, Monticelli F, Toledano M, \& Ferrari M (2012) Effects of post surface treatments on the bond strength of self-adhesive cements American Journal of Dentistry 25(3) 159-164.

24. Sloan FE (1992) Chemical attack of graphite/epoxy by hydrogen peroxide Applied Spectroscopy 46(3) 524-528. http://dx.doi.org/10.1366/0003702924125366.

25. Bronson SH, Hansen AR, Nielsen HZ, \& Woxen IK (2001) A comparative study of the immunogold labeling on $\mathrm{H}_{2} \mathrm{O}_{2}$ treated and heated epoxy sections Micron 32(2) 147-51. http://dx.doi.org/10.1016/S0968-4328(99)00107-9.

26. Kum KY, Lim KR, Lee CY, Park KH, Safavi KE, Fouad $\mathrm{AF}$, \& Spångberg LS (2004) Effects of removing residual peroxide and other oxygen radicals on the shear bond strength and failure modes at resin-tooth interface after tooth bleaching American Journal of Dentistry 17(4) 267-270.

27. Farmer DS, Burcham P, \& Marin PD (2006) The ability of thiourea to scavenge hydrogen peroxide and hydroxyl radicals during the intra-coronal bleaching of bloodstained root-filled teeth Australian Dental Journal 51(2) 146-152. http://dx.doi.org/10.1111/j.1834-7819. 2006.tb00418.x.

28. Aksornmuang J, Nakajima M, Senawongse P, \& Tagami J (2011) Effects of C-factor and resin volume on the bonding to root canal with and without fibre post insertion Journal of Dentistry 39(6) 422.429. http://dx.doi.org/10. 1016/j.dent.2011.03.007.

29. Mazzitelli C, Monticelli F, Toledano M, Ferrari M, \& Osorio R (2012) Effect of thermal cycling on the bond strength of self-adhesive cements to fiber posts Clinical Oral Investigations 16(3) 909-915. http://dx.doi.org/10. 1007/s00784-011-0576-1. 